\title{
Obesity as an independent predictive factor for pathologic complete response after neoadjuvant chemoradiation in rectal cancer
}

\author{
Soo Young Lee ${ }^{1}$, Chang Hyun Kim¹, Young Jin Kim¹, Han Deok Kwak², Jae Kyun Ju², Hyeong Rok Kim¹ \\ ${ }^{1}$ Department of Surgery, Chonnam National University Hwasun Hospital, Chonnam National University Medical School, Hwasun, \\ Korea \\ 2Department of Surgery, Chonnam National University Hospital, Chonnam National University Medical School, Gwangju, Korea
}

\begin{abstract}
Purpose: The predictive role of obesity on pathologic complete response (pCR) after neoadjuvant chemoradiation (nCRT) in rectal cancer remains controversial. This study aimed to evaluate the association between obesity and pathologic response in patients with rectal cancer following nCRT.

Methods: A total of 320 patients with primary rectal cancer who underwent curative resection after nCRT between January 2010 and September 2014 were enrolled in this study. Obesity was defined as body mass index of $\geq 25 \mathrm{~kg} / \mathrm{m}^{2}$. Clinicopathologic characteristics were analyzed to identify independent predictive factors for pCR.

Results: Among the included patients, $23.4 \%$ ( $n=75)$ were obese, and $14.7 \%(n=47)$ showed pCR. Baseline characteristics were generally similar between obese and nonobese patients, except that women $(P=0.001)$ and $c T 2$ tumors $(P=$ 0.001 ) were more common in the obese group. Multivariate logistic regression analysis revealed that obesity lodds ratio $[O R]=2.051 ; 95 \%$ confidence interval $[\mathrm{Cl}], 1.009-4.168)$, cT2 (OR, 3.614; $95 \% \mathrm{Cl}, 1.166-11.202)$, and pretreatment carcinoembryonic antigen $<5 \mathrm{ng} / \mathrm{mL}(\mathrm{OR}, 2.921 ; 95 \% \mathrm{Cl}, 1.365-6.253)$ were independent predictors for pCR. Obesity was not associated with disease-free survival or local recurrence-free survival.

Conclusion: Obesity was an independent predictive factor for pCR following nCRT in rectal cancer, but was not associated with recurrence. Further studies are needed to clarify the association between obesity and prognosis of rectal cancer after nCRT.
\end{abstract}

[Ann Surg Treat Res 2019;96(3):116-122]

Key Words: Rectal cancer, Obesity, Neoadjuvant chemoradiation

\section{INTRODUCTION}

Current guidelines suggest that adequate treatment of locally advanced rectal cancer consists of curative resection followed by neoadjuvant chemoradiation (nCRT) [1,2], which is associated with better local control [3] and possibly improved sphincter preservation [4]. Response to nCRT differs among patients with rectal cancer, with pathologic complete response (pCR) observed in $15 \%-20 \%$ of cases [5]. It is important to predict pCR to nCRT in locally advanced rectal cancer, because $\mathrm{PCR}$ is associated with not only a low rate of local recurrence but also favorable long-term survival $[5,6]$. Numerous clinical, radiologic, and molecular features have been investigated as possible predictors of pCR, but currently, no robust markers exist [7].
Received June 26, 2018, Revised September 18, 2018, Accepted October 16, 2018

Corresponding Author: Hyeong Rok Kim

Department of Surgery, Chonnam National University Hwasun Hospital, Chonnam National University Medical School, 322 Seoyang-ro, Hwasun 58128, Korea

Tel: +82-61-379-7643, Fax: +82-61-379-7661

E-mail:drkhr@chonnam.ac.kr

ORCID code: https://orcid.org/0000-0003-3747-1415
Copyright (c) 2019, the Korean Surgical Society

(c) Annals of Surgical Treatment and Research is an Open Access Journal. All articles are distributed under the terms of the Creative Commons Attribution NonCommercial License (http://creativecommons.org/licenses/by-nc/4.0/) which permits unrestricted non-commercial use, distribution, and reproduction in any medium, provided the original work is properly cited. 
Meanwhile, obesity has been reported to be associated with surgical outcomes following rectal cancer [8,9]. Because of the associated technical difficulties in performing total mesorectal excision, obesity was found to increase local recurrence as well as postoperative morbidity [8,9]. Also, obesity may decrease the possibility of sphincter preservation [8,9]. In addition, some studies reported a relationship between obesity and oncologic outcomes of patients with rectal cancer following nCRT, although their results were controversial [10-14]. Given the fact that obesity is associated with inflammation and angiogenesis [15] and is associated with the chronic oxidative stress [16], it is possible to consider the possibility that obesity is related to the response of radiotherapy. However, few previous studies reported the significance of obesity in predicting $\mathrm{PCR}$ after nCRT in rectal cancer [13].

Therefore, we designed the present study to investigate the possible association between obesity and pathologic response to nCRT, as well as subsequent oncologic outcomes in patients with rectal cancer.

\section{METHODS}

This study was approved and informed consent was waived by the Institutional Review Board of Chonnam National University Hwasun Hospital (CNUHH-2018-004). We retrospectively reviewed clinicopathologic data of patients with primary rectal cancer who underwent curative resection following nCRT between January 2010 and September 2014. Patients with distant metastasis were excluded. Obesity was defined as body mass index (BMI) of $\geq 25 \mathrm{~kg} / \mathrm{m}^{2}$ according to Asian BMI classification [17].

\section{Preoperative evaluation}

All patients were evaluated with serum CEA, colonoscopy, abdominopelvic and chest CT, pelvic MRI, and/or endorectal ultrasound for local staging. Prior to nCRT, rigid rectoscopy was used to assess the distance of the tumor from the anal verge, and this was classified into 3 groups: lower rectum $(0-5 \mathrm{~cm})$, middle rectum $(6-10 \mathrm{~cm})$, and upper rectum $(11-15 \mathrm{~cm})$. Both tumor circumferentiality and macroscopic ulceration were also determined by rigid rectoscopy by the attending surgeon. Macroscopic ulcerative tumors were defined as ulcerative, diffuse infiltrative, or annular constrictive rectal tumors, and circumferential tumors were defined as those involving $>75 \%$ of the circumference of the rectum [18]. Clinical tumor size, which means the maximal diameter of the tumor, was measured by endorectal ultrasound and/or pelvic MRI. Included patients received nCRT, which consisted of long-course radiation 5,040 cGy in 28 fractions) and concomitant 5-fluorouracil-based chemotherapy. Study inclusion criteria for nCRT administration were locally advanced rectal cancers (clinical diagnosis of $\geq \mathrm{T} 3$ or $\geq \mathrm{N} 1$ ) or low rectal cancer of cT2N0 for sphincter-preserving surgery.

\section{Surgery and adjuvant therapy}

Radical surgery was performed with curative intent 6-10

Table 1. Correlation between obesity and clinical variables

\begin{tabular}{|c|c|c|c|}
\hline Variable & $\begin{array}{c}\text { Nonobese } \\
(n=245)\end{array}$ & $\begin{array}{c}\text { Obese } \\
(n=75)\end{array}$ & P-value \\
\hline Sex & & & 0.001 \\
\hline Male & $176(71.8)$ & $38(50.7)$ & \\
\hline Female & $69(28.2)$ & $37(49.3)$ & 0.479 \\
\hline Age $(y r)$ & $63.5 \pm 11.0$ & $64.6 \pm 10.7$ & \\
\hline ASA PS classification & & & 0.428 \\
\hline I, II & $228(94.2)$ & 68 (91.9) & \\
\hline III, IV & $15(5.8)$ & $6(8.1)$ & \\
\hline Location & & & 0.936 \\
\hline Midupper rectum & $105(40.8)$ & $31(41.3)$ & \\
\hline Lower rectum & $145(59.2)$ & $44(58.7)$ & \\
\hline Clinical T stage & & & 0.001 \\
\hline cT2 & $7(2.9)$ & $9(12.0)$ & \\
\hline сT3 & $215(87.8)$ & $65(86.7)$ & \\
\hline cT4 & $23(9.4)$ & $1(1.3)$ & \\
\hline Clinical $N$ stage & & & 0.242 \\
\hline cNO & $94(38.4)$ & $33(44.0)$ & \\
\hline $\mathrm{cN} 1$ & $98(40.0)$ & $22(29.3)$ & \\
\hline $\mathrm{cN} 2$ & $53(21.6)$ & $20(26.7)$ & \\
\hline Clinical tumor size $(\mathrm{cm})$ & $4.5 \pm 1.4$ & $4.2 \pm 1.3$ & 0.054 \\
\hline Macroscopic ulceration & & & 0.999 \\
\hline No & $16(6.6)$ & $4(5.4)$ & \\
\hline Yes & $225(93.4)$ & $70(94.6)$ & \\
\hline Tumor circumferentiality & & & 0.262 \\
\hline No & $132(54.8)$ & $46(62.2)$ & \\
\hline Yes & $109(45.2)$ & $28(37.8)$ & \\
\hline Differentiation & & & 0.444 \\
\hline WD & $117(48.5)$ & $30(40.5)$ & \\
\hline MD & $115(47.7)$ & $40(54.1)$ & \\
\hline PD & $9(3.7)$ & $4(5.4)$ & \\
\hline Pretreatment CEA $(\mathrm{ng} / \mathrm{mL})$ & & & 0.499 \\
\hline$<5$ & $132(55.0)$ & $44(59.5)$ & \\
\hline$\geq 5$ & $108(45.0)$ & $30(40.5)$ & \\
\hline Surgical procedure & & & 0.691 \\
\hline Open & $8(3.3)$ & $1(1.3)$ & \\
\hline Laparoscopy & $237(96.7)$ & $74(98.7)$ & \\
\hline $\begin{array}{l}\text { Sphincter-preserving } \\
\text { surgery }\end{array}$ & & & 0.892 \\
\hline Preserved & $217(88.6)$ & $66(88.0)$ & \\
\hline Not preserved & $28(11.4)$ & $9(12.0)$ & \\
\hline Operative time (min) & & & 0.265 \\
\hline$<180$ & $142(58.0)$ & $38(50.7)$ & \\
\hline$\geq 180$ & $103(42.0)$ & $37(49.3)$ & \\
\hline
\end{tabular}

Values are presented as number (\%) or mean \pm standard deviation.

ASA PS, American Society of Anesthesiologists physical status; WD, well differentiated; MD, moderately differentiated; $P D$, poorly differentiated. 
weeks after the completion of radiotherapy. In all patients, surgery was conducted according to general oncologic principles. The surgeon in each case decided whether to perform abdominoperineal resection or sphincter-preserving surgery. Anastomosis was performed by either the double-stapling method or the hand-sewing method in very-low rectal cancer. Administration of adjuvant chemotherapy was determined by the medical oncologist based on the patient's condition. In general, 5-fluorouracil-based adjuvant chemotherapy was recommended for all patients regardless of their final pathologic stage.

\section{Pathologic examination}

The final pathologic features were restaged according to the seventh edition of the American Joint Committee on Cancer TNM staging system at the time of data review. We defined pCR as the absence of adenocarcinoma cells in the surgical specimen (ypTONO). Circumferential resection margin was determined to be positive in cases of margin $<1 \mathrm{~mm}$. Tumor regression grade was classified according to the Dworak/Rödel grading system [19].

\section{Follow-up}

Patients underwent follow-up every 3 months during the first 2 years, at 6-month intervals for the next 3 years, and annually thereafter. Serum CEA tests, abdominopelvic and chest CT, colonoscopy, and positron emission tomography were conducted on a semiannual basis or in cases of suspected recurrence. Recurrence was diagnosed via radiological detection of lesions with increasing size or by histological confirmation. Local recurrence was defined as recurrent disease in the pelvic cavity, including the anastomosis and lateral pelvic wall. Distant metastasis was defined as disease outside the pelvis.

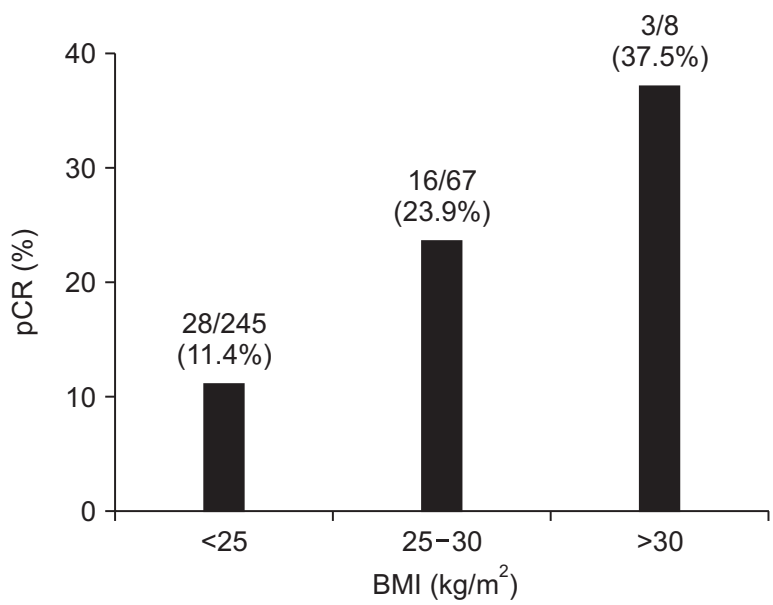

Fig. 1. Relationship between body mass index (BMI) and pathologic complete response (pCR) rate.

\section{Statistical analysis}

Categorical variables were compared using the chi-square test or Fisher exact test, and continuous variables were compared using Student t-test. Multivariate logistic regression analysis was also performed to explore predictive factors for $\mathrm{pCR}$.

Table 2. Univariate analysis of the predictive factors for pathologic complete response to neoadjuvant chemoradiation

\begin{tabular}{|c|c|c|c|}
\hline Variable & $\begin{array}{l}\text { Incomplete } \\
\text { response } \\
(\mathrm{n}=273)\end{array}$ & $\begin{array}{c}\text { Complete } \\
\text { response } \\
(\mathrm{n}=47)\end{array}$ & P-value \\
\hline Sex & & & 0.415 \\
\hline Male & $185(86.4)$ & $29(13.6)$ & \\
\hline Female & $88(83.0)$ & $18(17.0)$ & \\
\hline Age $(y r)$ & & & 0.417 \\
\hline$<70$ & $175(84.1)$ & 33 (15.9) & \\
\hline$\geq 70$ & $98(87.5)$ & $14(12.5)$ & \\
\hline Body mass index $\left(\mathrm{kg} / \mathrm{m}^{2}\right)$ & & & 0.003 \\
\hline$<25$ & $217(88.6)$ & $28(11.4)$ & \\
\hline$\geq 25$ & $56(74.7)$ & $19(25.3)$ & \\
\hline ASA PS classification & & & 0.999 \\
\hline I, II & $253(85.5)$ & $43(14.5)$ & \\
\hline III, IV & $17(85.0)$ & $3(15.0)$ & \\
\hline Location & & & 0.472 \\
\hline Midupper rectum & $114(87.0)$ & $17(13.0)$ & \\
\hline Lower rectum & $159(84.1)$ & $30(15.9)$ & \\
\hline Clinical T stage & & & $<0.001$ \\
\hline cT2 & $8(50.0)$ & $8(50.0)$ & \\
\hline сT3 & $241(86.1)$ & 39 (13.9) & \\
\hline cT4 & $24(100.0)$ & $0(0)$ & \\
\hline Clinical N stage & & & 0.105 \\
\hline $\mathrm{cNO}$ & $102(80.3)$ & $25(19.7)$ & \\
\hline $\mathrm{cN} 1$ & $105(87.5)$ & $15(12.5)$ & \\
\hline $\mathrm{cN} 2$ & $66(90.4)$ & 7 (9.6) & \\
\hline Clinical tumor size $(\mathrm{cm})$ & & & 0.012 \\
\hline$<5$ & $166(81.4)$ & 38 (18.6) & \\
\hline$\geq 5$ & $102(91.9)$ & $9(8.1)$ & \\
\hline Macroscopic ulceration & & & 0.516 \\
\hline No & $16(80.0)$ & $4(20.0)$ & \\
\hline Yes & $252(85.4)$ & $43(14.6)$ & \\
\hline Tumor circumferentiality & & & 0.003 \\
\hline No & $142(79.8)$ & $36(20.2)$ & \\
\hline Yes & $126(92.0)$ & $11(8.0)$ & \\
\hline Differentiation & & & 0.415 \\
\hline WD & $128(87.1)$ & $19(12.9)$ & \\
\hline MD & $128(82.6)$ & $27(17.4)$ & \\
\hline PD & $12(92.3)$ & $1(7.7)$ & \\
\hline Pretreatment CEA (ng/mL) & & & 0.001 \\
\hline$<5$ & $139(79.0)$ & $37(21.0)$ & \\
\hline$\geq 5$ & $128(92.8)$ & $10(7.2)$ & \\
\hline
\end{tabular}

Values are presented as number $(\%)$ or mean \pm standard deviation.

ASA PS, American Society of Anesthesiologists physical status; WD, well differentiated; MD, moderately differentiated; PD, poorly differentiated. 
Survival rates were estimated and compared using the KaplanMeier method and log-rank test. The Cox proportional hazard model was utilized for multivariate survival analysis. Results were considered significant at $\mathrm{P}<0.05$. Statistical analyses were conducted using IBM SPSS Statistics ver. 22.0 (IBM Co., Armonk, NY, USA).

\section{RESULTS}

Among the 320 patients included, 75 (23.4\%) were classified as obese. Table 1 shows the baseline characteristics of the patients according to obesity status. In general, clinical variables were similar between obese and nonobese patients, except that more women $(49.3 \%$ vs. $28.2 \%, \mathrm{P}=0.001)$ and more $\mathrm{CT} 2$ disease $(12.0 \%$ vs. $2.9 \%, \mathrm{P}=0.001)$ were found among the obese

Table 3 Multivariate analysis of the predictive factors for pathologic complete response to neoadjuvant chemoradiation

\begin{tabular}{lll}
\hline \multicolumn{1}{c}{ Variable } & Adjusted OR $(95 \% \mathrm{Cl})$ & P-value \\
\hline Body mass index $\left(\mathrm{kg} / \mathrm{m}^{2}\right), \geq 25$ vs. $<25$ & $2.051(1.009-4.168)$ & 0.047 \\
Clinical T stage, cT2 vs. cT3 or cT4 & $3.614(1.166-11.202)$ & 0.026 \\
Clinical tumor size $(\mathrm{cm}),<5$ vs. $\geq 5$ & $1.322(0.543-3.221)$ & 0.538 \\
Tumor circumferentiality, no vs. yes & $2.039(0.895-4.647)$ & 0.090 \\
Pretreatment CEA $(\mathrm{ng} / \mathrm{mL}),<5$ vs. $\geq 5$ & $2.921(1.365-6.253)$ & 0.006 \\
\hline
\end{tabular}

$\mathrm{OR}$, odds ratio; $\mathrm{Cl}$, confidence interval.

Table 4. Association between obesity and survival outcomes

\begin{tabular}{|c|c|c|c|c|c|c|c|c|}
\hline \multirow{3}{*}{ BMI $\left(\mathrm{kg} / \mathrm{m}^{2}\right)$} & \multicolumn{4}{|c|}{ Univariate analysis } & \multicolumn{4}{|c|}{ Multivariate analysis ${ }^{\mathrm{a})}$} \\
\hline & \multicolumn{2}{|c|}{ DFS } & \multicolumn{2}{|c|}{ LRFS } & \multicolumn{2}{|l|}{ DFS } & \multicolumn{2}{|l|}{ LRFS } \\
\hline & $\begin{array}{c}\text { 3-Year } \\
\text { DFS (\%) }\end{array}$ & P-value & $\begin{array}{c}\text { 3-Year } \\
\text { LRFS (\%) }\end{array}$ & P-value & $\begin{array}{c}\mathrm{HR} \\
(95 \% \mathrm{Cl})\end{array}$ & P-value & $\begin{array}{c}\mathrm{HR} \\
(95 \% \mathrm{Cl})\end{array}$ & P-value \\
\hline$\geq 25(n=75)$ & 71.4 & 0.397 & 90.6 & 0.429 & & & & \\
\hline$<25(n=245)$ & 69.7 & - & 88.2 & - & & & & \\
\hline$\geq 25$ vs. $<25$ & & & & & $0.816(0.484-1.375)$ & 0.445 & $0.441(0.151-1.291)$ & 0.135 \\
\hline
\end{tabular}

DFS, disease-free survival; LRFS, local recurrence-free survival; BMI, body mass index; HR, hazard ratio; Cl, confidence interval.

${ }^{\mathrm{a}}$ Included covariables were tumor location, ypT stage, ypN stage, perineural invasion, tumor differentiation, circumferential resection margin, and tumor regression grade.
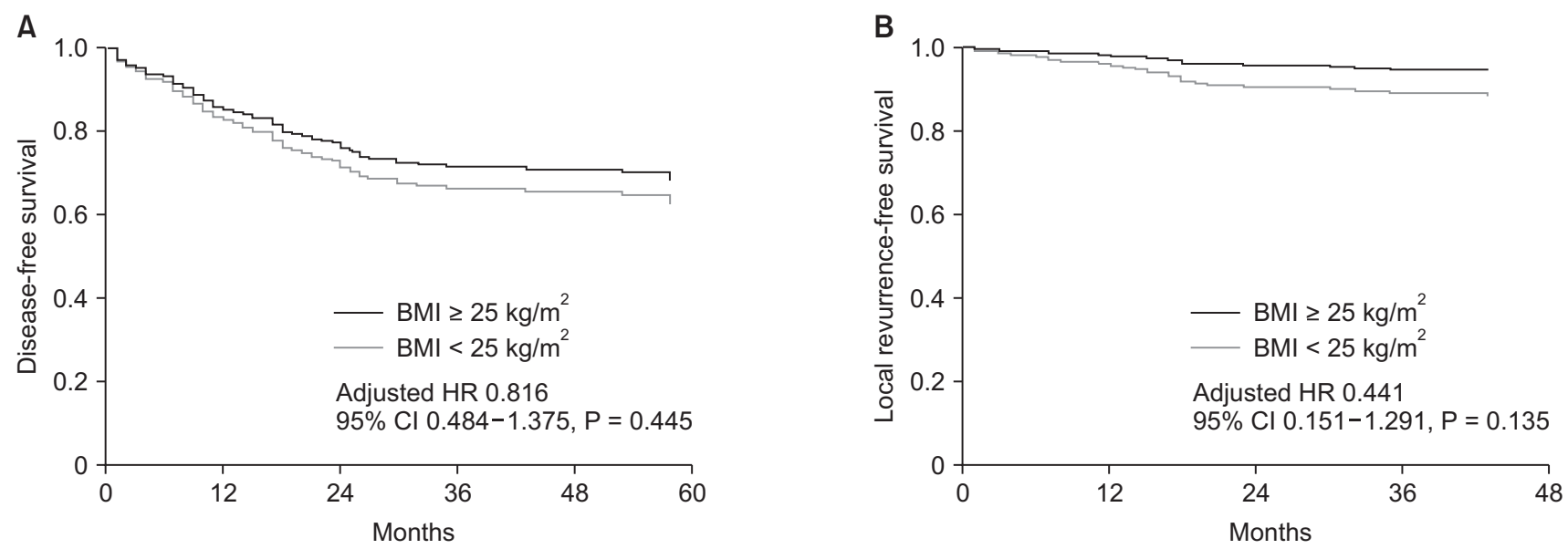

Fig. 2. Multivariate Cox proportional hazards curves of disease-free survival (A) and local recurrence-free survival (B) according to body mass index (BMI). Covariables included tumor location, ypT stage, ypN stage, perineural invasion, tumor differentiation, circumferential resection margin, and tumor regression grade. HR, hazard ratio; Cl, confidence interval. 
patients.

A total of 47 patients (14.7\%) showed pCR. When analyzing the relationship between $\mathrm{BMI}$ and $\mathrm{pCR}$, the higher the $\mathrm{BMI}$, the higher the pCR ratio (BMI $<25,25-30$, and $\geq 30 \mathrm{~kg} / \mathrm{m}^{2}$; pCR 11.4\%, 23.9\%, and 37.5\%, respectively) (Fig. 1). We analyzed associations between clinical variables and pathologic response to $\mathrm{nCRT}$, and found that BMI $\geq 25 \mathrm{~kg} / \mathrm{m}^{2}$ ( $25.3 \% \mathrm{vs} .11 .4 \%, \mathrm{P}=$ 0.003), clinical T stage (cT2, 50.0\% vs. cT3, $13.9 \%$, and cT4, $0 \%, \mathrm{P}$ $<0.001)$, clinical tumor size $(<5 \mathrm{~cm}, 18.6 \%$ vs. $\geq 5 \mathrm{~cm}, 8.1 \%, \mathrm{P}$ $=0.012)$, tumor circumferentiality ( $8.0 \%$ vs. $20.2 \%, \mathrm{P}=0.003)$, and pretreatment CEA ( $<5 \mathrm{ng} / \mathrm{mL}, 21.0 \%$ vs. $\geq 5 \mathrm{ng} / \mathrm{mL}, 7.2 \%$, $\mathrm{P}=0.001$ ) were related to $\mathrm{pCR}$ rate (Table 2). On multivariate logistic regression, obesity (adjusted odds ratio [OR], 2.051; 95\% confidence interval [CI], 1.009-4.168), cT2 (adjusted OR, 3.614; 95\% CI, 1.166-11.202), and pretreatment carcinoembryonic antigen $<5 \mathrm{ng} / \mathrm{mL}$ (adjusted OR, 2.921; 95\% CI, 1.365-6.253) were independent predictors for pCR (Table 3).

After a median follow-up period of 42 months (range, 1-83 months), 99 patients (30.9\%) experienced recurrence, and 33 of these $(10.3 \%)$ had local recurrence. The overall rates of diseasefree survival (DFS) and local recurrence-free survival (LRFS) at 3 years were $67.4 \%$ and $88.8 \%$, respectively. Table 4 summarizes the results of univariate and multivariate survival analyses for DFS and LRFS. Obese patients had a tendency toward better DFS (71.4\% vs. $69.7 \%, P=0.397)$ and LRFS (90.6\% vs. $88.2 \%$, $\mathrm{P}=0.429)$ compared with nonobese patients, although these findings were not statistically significant. On multivariate survival analysis, obesity was not associated with either DFS (hazard ratio [HR], 0.816; 95\% CI, 0.484-1.375; $\mathrm{P}=0.445$ ) or LRFS (HR, 0.441; 95\% CI, 0.151-1.291; $\mathrm{P}=0.135$ ) (Fig. 2).

\section{DISCUSSION}

In the present study, we investigated the association between obesity and PCR following nCRT in patients with rectal cancer. Obesity was an independent predictor of pCR after adjusting for possible confounders, although it was not associated with recurrence.

The association between obesity and cancer recurrence has been widely investigated in breast cancer, and was shown to be associated with local recurrence, distant metastasis, and decreased overall survival [20-22]. One possible reason for these findings is that increased adipose tissue may elevate the levels of circulating estrogens, insulin, and insulin-like growth factors, which can facilitate cancer cell growth [22]. In contrast, some studies have reported that obesity was associated with better prognosis after chemoradiation in other types of cancers, such as cervical cancer, lymphoma, and head and neck cancers [23-27]. These studies commonly suggested that better survival in obese patients might be caused by better tolerance to chemoradiation and/or surgery. Patients with higher BMI may withstand the inevitable weight loss after treatment including chemoradiation [26], and underweight patients may be more likely to suffer from comorbidities because of their weakened immune systems [27], factors that could result in survival differences.

On the other hand, there have been only a few studies reporting on associations between obesity and oncologic outcomes in rectal cancer following nCRT [10-14]. Three studies demonstrated poorer survival and/or a lower rate of $\mathrm{pCR}$ in obese patients [11-13], whereas one study reported similar survival outcomes between obese and nonobese patients [10], and a recent study even reported that obesity was an independent favorable prognostic factor for DFS in patients with rectal cancer treated with nCRT [14]. These studies reported conflicting results, and some were limited by their small sample sizes $[11,12,14]$. In the present study, we showed that obesity was an independent predictor of pCR. In addition, although multivariate survival analysis showed that obesity was not associated with DFS and LRFS, a tendency (HR, 0.441; 95\% CI, 0.151-1.291) was observed between obesity and better LRFS (Table 4, Fig. 2). As is widely known, pCR brings about desirable oncologic outcomes [5,6]. Therefore, if obesity brings a higher rate of $\mathrm{PCR}$, it is likely that obesity is associated with better DFS or LRFS. Considering the association between obesity and PCR, a possible hidden relationship between obesity and improved oncologic outcomes must be investigated by means of future large-scale studies.

The reason for the close relationship between obesity and response to radiotherapy is uncertain. One possible explanation is that obesity is associated with a state of chronic inflammation. In adipose tissue in obese patients, the number of macrophages and subsequent production of inflammatory cytokines are increased [28]. In other words, excessive adipose tissue in obese patients is associated with inflammation, angiogenesis, and immune cell infiltration [15]. This interplay between obesity and immune response may alter the tumor microenvironment and increase the tumor response to radiotherapy [26]. Furthermore, obesity is related to increased levels of free fatty acids, which may stimulate the production of reactive oxygen species. Obesity-induced chronic oxidative stress may induce epigenetic alterations, which could result in a different response to radiotherapy [16]. Another possible mechanism is a hidden interaction between obesity and molecular signaling pathways. Gomez-Millan et al. [14] recently reported that patients with rectal cancer who expressed nuclear $\beta$-catenin showed better DFS after nCRT than those who did not express $\beta$-catenin. Nuclear $\beta$-catenin has been reported to be associated with better cancer-specific and overall survival in obese patients [29]. Therefore, alterations of key components in the Wnt/ $\beta$-catenin signaling pathway caused by dietinduced obesity may be a possible reason for the relationship between obesity and the response to radiotherapy [28]. Further 
translational research may be needed to investigate this issue.

There are some limitations in the present study. As described above, the group of obese participants included higher percentage of patients with cT2 disease, which may represent a selection bias. To overcome this confounding effect, we performed multivariate logistic regression analysis and showed that both CT2 disease and obesity were independent predictive factors for pCR. Therefore, we strongly believe that the results of the present study are still meaningful. Another limitation is that we could not elucidate the exact mechanism underlying the relationship between obesity and better response to radiotherapy. Therefore, there is still a possibility that the results of this study may not reflect the actual phenomenon, but merely a result of statistical analysis. Nevertheless, a strength of this study is that it is one of the rare studies reporting an association between obesity and pathologic response in rectal cancer after nCRT.

In conclusion, obesity was an independent predictive factor for $\mathrm{pCR}$ after nCRT in rectal cancer, although it was not associated with recurrence. Further studies to explore the mechanism of the relationship between obesity and pathologic response to $\mathrm{nCRT}$ are warranted.

\section{CONFLICTS OF INTEREST}

No potential conflict of interest relevant to this article was reported.

\section{REFERENCES}

1. National Comprehensive Cancer Network. Rectal cancer clinical practice guidelines in oncology [Internet]. Fort Wathington (PA): National Comprehensive Cancer Network; c2018 [cited 2018 May 1]. Available from: http://www.nccn.org/ professionals/physician_gls/pdf/rectal.pdf.

2. Glimelius B, Tiret E, Cervantes A, Arnold D; ESMO Guidelines Working Group. Rectal cancer: ESMO Clinical Practice Guidelines for diagnosis, treatment and followup. Ann Oncol 2013;24 Suppl 6:vi81-8.

3. Sauer R, Becker H, Hohenberger W, Rodel C, Wittekind C, Fietkau R, et al. Preoperative versus postoperative chemoradiotherapy for rectal cancer. $\mathrm{N}$ Engl J Med 2004:351:1731-40.

4. Gerard JP, Chapet O, Nemoz C, Hartweig J, Romestaing P, Coquard R, et al. Improved sphincter preservation in low rectal cancer with high-dose preoperative radiotherapy: the lyon R96-02 randomized trial. J Clin Oncol 2004;22:2404-9.

5. Martin ST, Heneghan HM, Winter DC. Systematic review and meta-analysis of outcomes following pathological complete response to neoadjuvant chemoradiotherapy for rectal cancer. $\mathrm{Br}$ J Surg 2012;99:918-28.

6. Zorcolo L, Rosman AS, Restivo A, Pisano M, Nigri GR, Fancellu A, et al. Complete pathologic response after combined modality treatment for rectal cancer and long-term survival: a meta-analysis. Ann Surg Oncol 2012;19:2822-32.

7. Ryan JE, Warrier SK, Lynch AC, Ramsay RG, Phillips WA, Heriot AG. Predicting pathological complete response to neoadjuvant chemoradiotherapy in locally advanced rectal cancer: a systematic review. Colorectal Dis 2016;18:234-46.

8. Meyerhardt JA, Tepper JE, Niedzwiecki D, Hollis DR, McCollum AD, Brady D, et al. Impact of body mass index on outcomes and treatment-related toxicity in patients with stage II and III rectal cancer: findings from Intergroup Trial 0114. J Clin Oncol 2004:22:648-57.

9. You JF, Tang R, Changchien CR, Chen JS, You YT, Chiang JM, et al. Effect of body mass index on the outcome of patients with rectal cancer receiving curative anterior resection: disparity between the upper and lower rectum. Ann Surg 2009; 249:783-7.

10. Chern H, Chou J, Donkor C, Shia J, Guillem JG, Nash GM, et al. Effects of obesity in rectal cancer surgery. J Am Coll Surg 2010;211:55-60.

11. Clark W, Siegel EM, Chen YA, Zhao X, Parsons CM, Hernandez JM, et al. Quantitative measures of visceral adiposity and body mass index in predicting rectal cancer outcomes after neoadjuvant chemoradiation. J Am Coll Surg 2013;216:107081.

12. Choi Y, Lee YH, Park SK, Cho H, Ahn KJ. Association between obesity and local control of advanced rectal cancer after combined surgery and radiotherapy. Radiat Oncol J 2016;34:113-20.

13. Park IJ, You YN, Skibber JM, RodriguezBigas MA, Das P, Eng C, et al. Oncologic and functional hazards of obesity among patients with locally advanced rectal cancer following neoadjuvant chemoradiation therapy. Am J Clin Oncol 2017;40: 277-82.

14. Gomez-Millan J, Queipo MI, Del Mar Delgado M, Perez-Villa L, Roman A, De la Portilla F, et al. The impact of body mass index and nuclear $\beta$-catenin on survival in locally advanced rectal cancer treated with preoperative radiochemotherapy. J Surg Oncol 2017;115:301-6.

15. Incio J, Tam J, Rahbari NN, Suboj P, McManus DT, Chin SM, et al. PlGF/ VEGFR-1 signaling promotes macrophage polarization and accelerated tumor progression in obesity. Clin Cancer Res 2016; 22:2993-3004.

16. Vares G, Wang B, Ishii-Ohba H, Nenoi M, Nakajima T. Diet-induced obesity 
modulates epigenetic responses to ionizing radiation in mice. PLoS One 2014; 9:e106277.

17. WHO Expert Consultation. Appropriate body-mass index for Asian populations and its implications for policy and intervention strategies. Lancet 2004:363:15763.

18. Huh JW, Kim HR, Kim YJ. Clinical prediction of pathological complete response after preoperative chemoradiotherapy for rectal cancer. Dis Colon Rectum 2013;56:698-703.

19. Rodel C, Martus P, Papadoupolos T, Fuzesi L, Klimpfinger M, Fietkau R, et al. Prognostic significance of tumor regression after preoperative chemoradiotherapy for rectal cancer. J Clin Oncol 2005:23:8688-96.

20. Ewertz M, Jensen MB, Gunnarsdottir KA, Hojris I, Jakobsen EH, Nielsen D, et al. Effect of obesity on prognosis after earlystage breast cancer. J Clin Oncol 2011;29: 25-31.

21. Chan DS, Vieira AR, Aune D, Bandera EV, Greenwood DC, McTiernan A, et al. Body mass index and survival in women with breast cancer-systematic literature review and meta-analysis of 82 follow-up studies. Ann Oncol 2014:25:1901-14.

22. Bergom C, Kelly T, Bedi M, Saeed H, Prior P, Rein LE, et al. Association of locoregional control with high body mass index in women undergoing breast conservation therapy for early-stage breast cancer. Int J Radiat Oncol Biol Phys 2016;96:65-71.

23. Kizer NT, Thaker PH, Gao F, Zighelboim I, Powell MA, Rader JS, et al. The effects of body mass index on complications and survival outcomes in patients with cervical carcinoma undergoing curative chemoradiation therapy. Cancer 2011;117: 948-56.

24. Huang PY, Wang CT, Cao KJ, Guo X, Guo L, Mo HY, et al. Pretreatment body mass index as an independent prognostic factor in patients with locoregionally advanced nasopharyngeal carcinoma treated with chemoradiotherapy: findings from a randomised trial. Eur J Cancer 2013;49: 1923-31.

25. Takenaka Y, Takemoto N, Nakahara S, Yamamoto Y, Yasui T, Hanamoto A, et al. Prognostic significance of body mass index before treatment for head and neck cancer. Head Neck 2015;37:1518-23.

26. Albergotti WG, Davis KS, Abberbock S, Bauman JE, Ohr J, Clump DA, et al. Association of pretreatment body mass index and survival in human papillomavirus positive oropharyngeal squamous cell carcinoma. Oral Oncol 2016;60:55-60.

27. Liu J, Deng YT, Zhang L, Li N, Jiang M, Zou LQ, et al. Body mass index as a prognostic factor in patients with extranodal natural killer/T-cell lymphoma, nasal type. Oncotarget 2016;7:78159-67.

28. Liu Z, Brooks RS, Ciappio ED, Kim SJ, Crott JW, Bennett G, et al. Diet-induced obesity elevates colonic TNF- $\alpha$ in mice and is accompanied by an activation of Wnt signaling: a mechanism for obesityassociated colorectal cancer. J Nutr Biochem 2012:23:1207-13.

29. Morikawa T, Kuchiba A, Yamauchi M, Meyerhardt JA, Shima K, Nosho K, et al. Association of CTNNB1 (beta-catenin) alterations, body mass index, and physical activity with survival in patients with colorectal cancer. JAMA 2011;305:1685-94. 